\title{
Research on Slow Fashion Concept and Its Impact on Modern Footwear
}

\section{Eco-Design}

\author{
Yugang Chen ${ }^{1, a}$ \\ ${ }^{1}$ Jiangxi Institute of Fashion Technology, Jiangxi, Nanchang, 330201 \\ ${ }^{\mathrm{a}}$ email
}

Keywords: Slow Fashion, Footwear, Eco-design, Impact

\begin{abstract}
Slow fashion philosophy is a product of society and fashion development, which can highlight a person's unique taste and temperament compared to the fast fashion. Slow fashion has many positive effects for human society, such as help to protect the environment, enhance the creativity of fashion industry and so on. This paper analysis the concepts of slow fashion and the manifestations of modern footwear eco-design and do the relevant discussion on influence of slow fashion ideas on issues such as eco-design footwear. It intended to advocate a more thoughtful approach to design for modern footwear designer, and create space for the living environment according to the concept of environmental protection, ecology concept and values of sustainable development.
\end{abstract}

\section{Introduction}

With the advent of low-carbon economy, protecting the environment for human beings more and more attention, such as strengthening the awareness of environmental protection publicity and actively promote low-carbon life, and in the modern product design is the pursuit of a return to nature, close , healthy, environmentally friendly design. Coupled with the gradual rise of the global "slow life" movement, more and more people accept this slow food, slow love, slow motion, slow travel, slow fashion lifestyle, slow fashion design philosophy is to produce and in this context development. Slow fashion is not only a more creative, personalized and practical design, but also for the ecology of human society and a pursuit of harmony with nature, a way of life.

China is the world's footwear production, exporting countries, shoe companies are taking a long-term "high input, high consumption, high pollution," the road is a lot of years of rapid growth in energy consumption, the environment and the high cost of sacrifices made. In recent years, we have come to realize the importance of the environment for human survival, many shoe companies change their ideas and start implementing environmental awareness in footwear production, the implementation of footwear "green production", eco-design, prohibit the use of environmental pollution raw materials, instead of using renewable materials as raw materials, products can not only be recycled, the environment will not bring pollution to consumers in order to warm, comfortable feeling. Slow fashion philosophy is to require the development of social and cultural pluralism and more importantly, it fits the current international design trends, but also will have a profound influence on modern footwear eco-design.

\section{The Concept of Slow Fashion}

Slow fashion means relative to a design in terms of fast fashion, consumer and lifestyle concepts, 
adhering to creativity, individuality and practical eco-design concept. Slow fashion is a state of mind to pursue lifestyle in harmony with nature, in the field of fashion with a higher quality of life requires treat all acts and things, focus on sustainable development and urban lifestyle real life. Slow fashion people use items slowed elimination rate, which means slowing consumption, pollution people resources environment.

Slow emergence and development of eco-fashion design influenced by three main factors: first, the technology factor. Development of technology for the slow fashion concept provides technical support, such as improved production tools footwear, footwear materials innovation and footwear design changes and so on. And development of technology makes the shoe industry products designed to provide more comprehensive services, reflecting the personalized needs. Second, there are some economic factors. With the rapid economic development, improving people's living standards, consumer attitudes are consequent changes in swept frugal people's lives again. People no longer only the pursuit of price and popularity, but more hope both personalized footwear product design but also to have the characteristics of environmental protection, and practical aspects. Third, it is the network communication factor. The rapid development of today's information technology network media, fashion design makes the slow propagation speed, fashion trends change faster, above which to some extent contributed to the spread and development of the concept of slow fashion.

Slow fashion ideas have many beneficial effects for the development of China's shoe-making enterprises. First, slow fashion philosophy is built on top of the Earth's ecology, conducted footwear designed according to this concept, the idea is not only fashion, but also reflects the harmonious development of man and nature. Second, slow fashion ideas can effectively slow down the "metabolism", optimize the industrial resources, emphasizing the rational use of resources to maximize avoid waste, which will help mitigate the adverse effects on the environment shoe companies, and to promote the footwear industry development of creativity. The slow fashion concept also can effectively weaken consumer desire to buy, changes in consumer psychology and attitude, allowing consumers to create their own fashion, while revealing the personality and accomplishments. Finally, slow fashion concept will gradually change people's way of life, and promote people to re-examine their own lives and positioning, develop a positive and optimistic and relaxed attitude to life [1].

\section{The Ideas and Forms of Slow Fashion Modern Footwear Ecological Design}

The Concept of Slow Fashion Modern Footwear Ecological Design. Slow-fashion footwear concept of ecological design, in fact, is a "slow life" concept embodied in among. First, slow fashion footwear eco-design does not represent a matter of time, and its emphasis is an attitude and understanding of designers. Designers need to comply with the true heart of the original idea, and combine footwear eco-design works correctly grasp on me, affecting all aspects of the environment. Second, slow fashion footwear eco-design concept is no longer just the blind pursuit of fashion and popular, but a manifestation of wisdom. It requires footwear designer hearts and lives for social responsibility, the final design works out enough streamlined, durable, energy-saving, safety, ecology. Furthermore, slow fashion footwear requires the choice of fabric using environmentally friendly renewable materials, thus contributing to a low-carbon economy. Finally, the concept of slow fashion footwear under the Eco-design requirements for simple but not simple, and very concerned about the details of the design, both to meet the footwear fashion, but also consistent with the original eco-design concept.

The Manifestations of Slow Fashion Modern Footwear Eco-Design. Footwear ecological 
design conducted under slow fashion ideas mainly in the following aspects:

First, slow fashion design to promote environmental protection and sustainable development. Slow fashion philosophy advocating the use of a wide range of shoe materials, shoe materials to develop renewable and fully utilize and optimize existing resources, based on the above protecting the ecological environment and promote the concept of slow fashion footwear under the environmentally friendly design and sustainable development. Footwear ecological design focus will be towards the classic, durable, sophisticated slow fashion footwear design direction. One-sided pursuit of short-term economic benefits by reducing the waste of resources roughing footwear behavior will become a classic footwear product design, thus extending the time people dress, but also the achievements of the eco-friendly.

Second, focus on improving the quality of eco-design footwear. Part of the footwear designed to focus only on the harvest price, the corresponding reduction in the quality of the footwear design requirements. Slow fashion philosophy is exactly the opposite, which attaches great importance to product quality footwear, but also practical, durable, personality, and environmental protection. Slow fashion designer concept requires constant discovery footwear design elements from all aspects of life, experience, etc., to enhance innovation and originality, but it also reflects the way the designers of professional knowledge and personal accomplishment.

Third, eco-design requirements for footwear and classic style towards a low-carbon direction. Because conducted under slow eco-design footwear fashion ideas, fashion footwear is necessary to consider the aesthetic and consistent with the public, but also pay attention to the design of which reflects an eco-design concept. We want natural, historical and other aspects to look for inspiration, they need the help of advanced technology, past, present and future merging design concept, reflecting the diversity of footwear design, rich content on a classic footwear design works.

\section{The Application of Slow Fashion Design Ideas in Modern Footwear Eco-Designs}

The Footwear Fabric Is of Low Carbon. Footwear ecological design conducted under the concept of slow fashion, using low-carbon fabric is designed prerequisite. Carbon fabric means low energy consumption, carbon use less air pollution index is low, easily degraded or renewable fabrics. Low-carbon fabrics including renewable materials, natural fibers, such as animals and plants. Our common environmental fabric such as organic cotton, bamboo fiber, soybean protein fiber, organic wool. Not only do we require fabric material selection during footwear designed to meet the low-carbon eco-requirements, and the requirements on the design and processing also try to meet the development trend of low-carbon economy.

Footwear designed for use in animal skins such materials, there has been a huge controversy. Today, most of the artificial leather in the use of complete degradation difficult and recyclable utilization is low. Use natural animal leather and protect wildlife and conflict, does not meet the harmonious and sustainable development concept. So far as possible toward the top of the development of biodegradable synthetic leather on leather footwear fabric development, and is committed to improving its recycling rate. RPET recycled materials such as fabric, also known as the "Coke bottle" fabric. This recycling of scrap fabric selection Coke bottle, which was clean, renewable fiber made after dissolution, most of which are made of acetate fibers, and this fiber can be recycled, fashion designers made their footwear has become the highlight of the design as a profession. We will acetate fibers and conventional polyester fabric compared to the savings in energy consumption of more than eighty percentile. A "Coke bottle" fabric produced footwear, we wear out later, it can be recycled into new fabric and dissolved again, recycling, saves resources, but also protect the environment. 
Footwear Ecological Design Is Emotional. Footwear designer footwear products undeniable will show true feelings, only in footwear design which includes plenty of emotion to be able to make footwear products with more content, more vitality. Footwear under the concept of eco-design requirements for slow fashion designers must get rid of utilitarian mind, assume certain social responsibilities, and footwear designed to give life and emotion. First, designers need to have accurate positioning of class, age and other aspects of the work facing the ultimate footwear were thoughts, and catch the special nature and needs of these groups, from the spiritual and emotional above impress consumers, seize the consumer, footwear designed to enhance the cultural value of the works. Such as creative design of old Beijing cloth shoes, it will a rich history and culture and stylish atmosphere combined with its unique shape will be incorporated in the original design of emotion among the minimalist, natural style revealing a hint of elegance, there is a return to the original world of pure feeling [2].

Secondly, the design not only requires the designer footwear design capabilities, but also its own cultivation also has certain requirements. Based on their emotions, fashion sense, etc., combined with face footwear product characteristics and needs of the people, in order to maximize the meet consumer demands for the purpose of innovative design.

Footwear Eco-Design Is of Taste. It is not just for the pursuit of fashion footwear in order to meet practical, but a way to improve their taste and value, create a good image of the demand. So the concept of slow fashion designer also required when making the footwear design, footwear must taste of the core design. Design is not mechanically, not be able to blunt the different elements blend together, but both require creativity and requirements beautifully. In the use of color, footwear version, material use, etc., we need to have a full consideration, reflecting the taste, design innovative classic footwear. This requires footwear designers and continuously improve their professional knowledge, collect all aspects of materials and information in order to expand their horizons. While improving their capabilities and aesthetic sensibility of the new things, and ultimately the formation of a unique design [3].

Footwear Ecological Design Is of Market. After the completion of footwear design, will eventually need to market, so it must take full account of market factors. To combine fashion footwear market trend, increasing innovative footwear designs and originality in order to improve market competitiveness. And to do a balance between costs and profits, both to meet market and consumer demand, but also to meet the footwear business development and improve economic efficiency and competitiveness needs.

The Way of Dress Is Diversify. Make footwear design requirements attention to environmental protection and practicality, so the design can also consider diversification in the way they dress in under slow fashion concept. For example, through the demolition of footwear to achieve different length boots, the seasonal transition purposes require different footwear and other aspects. This will not only be able to protect the footwear practicality, and have some environmental effect. Another example can also use the same version of the type of footwear to be changed on the details, the way they dress in order to increase the diversity of [4].

\section{Conclusions}

With the advent of low-carbon economy, the modern footwear eco-design should follow the trend, and slow fashion concept undoubtedly not only meets the development trend, but also with the pursuit of people improving the self-image for the fashion. This requires the footwear designer use the slow fashion concept in later designs, self-rising literacy and improve the aesthetic ability, combined footwear design with the age as well as the market. 


\section{References}

[1] Renfei Gu: China Leather, Vol. 3 (2013) No 22, p.93-96

[2] Shiyue Chen: West Leather, Vol. 4 (2010) No 13, p.34-36

[3] Yinghua Ma, Dongsheng Xin: Leather Science and Engineering, Vol. 6 (2013) No 13, p.45-47

[4] Qianlin: urban architecture, Vol. 10 (2013). No10, p12-14 